\title{
EL DIABLO EN EL ORIGEN MÍTICO DE LAS PASIONES (PRIMERA PARTE: DE HOMERO A DESCARTES) ${ }^{1}$
}

\author{
Jorge Brenes Morales
}

\begin{abstract}
RESUMEN
En este artículo se hace un recorrido desde los griegos hasta Descartes para mostrar de qué modo la problemática occidental de las pasiones ha estado circunscrita en el mito y llega a depender directamente de la figura del Diablo.
\end{abstract}

ABSTRACT

In this article, the first of three, a review is made from the Greeks up to Descartes in order to show in whatever way the western problem of passion which has been circumscribed in myth and is directly dependent on the figure of the devil.

\section{Introducción: los comienzos de una problemática bifronte}

La antigua Grecia mostró ante el mito una actitud ambivalente: por un lado, de complacencia; por otro, de rechazo. Los poemas más extensos de Homero, la Ilíada y la Odisea, fueron el punto de divergencia. Mucho antes de conocer la escritura en un sentido convencional, estos poemas llegaron a constituir una especie de común denominador mítico del que prácticamente ningún griego hubiera querido sustraerse. Sin embargo, la reacción contra la poesía de Homero se produjo. Esta reacción estuvo a cargo de los presocráticos y desembocó en una cuestión que todavía no deja de tener consecuencias en lo que al mito se refiere.

Con Jenófanes de Colofón a la cabeza, los presocráticos se pronunciaron contra el mito. Ellos consideraron que la divinidad mostrada por Homero era en extremo indecorosa. Ante todo, les incomodó que los dioses no fueran uno solo y que se comportaran como seres humanos. Politeísmo y antropomorfismo fueron los defectos hallados por los presocráticos en los versos de Homero. Por estos defectos, el mito debía ser tomado con reservas, cuando no del todo rechazado.

Por su actitud ante Homero, Jenófanes se hizo merecedor del término Homeropates, sobrenombre que significa "pisoteador de Homero". Para Heráclito, Homero era digno de ser azotado. Tal vez para honrar este deseo de Heráclito, a los nueve libros de la obra de Zoilo de Anfípolis, titulada Contra la poesía de Homero, se les dio el nombre de "látigo de Homero". 
En este contexto de la crítica presocrática, surge por primera vez en Occidente el logos con un sentido de oposición a mito desconocido anteriormente entre los griegos. A la confluencia de una vertiente religiosa y otra científica -los presocráticos fueron al mismo tiempo teólogos y filósofos de la naturaleza- se sumó una vertiente gramatical sin la cual no habría sido posible definir por primera vez un sentido del logos en contradicción con el mito.

Los presocráticos se escandalizaron ante la poesía de Homero. Presentar a los dioses como hombres, supeditados por lo tanto a toda clase de placeres y a las más diversas intrigas, fue juzgado como el colmo de la indecencia. Pero los gramáticos proporcionaron a los presocráticos el remedio contra el escándalo. Este remedio se conoce como método alegórico de interpretación. Según los gramáticos, Homero resultaba indecente porque no se lo leía alegóricamente.

Para aplicar este método de interpretación, basta con suponer dos niveles de sentido en el mito: uno superficial y otro profundo; uno literal y otro subyacente a la letra. En la superficie se encuentra el mito; en la profundidad, la alegoría propiamente dicha. Las circunstancias en que ha surgido este método de interpretación impiden poner en duda la finalidad moralista que desde entonces lo anima.

Desde luego, si el mito pudiera ser extirpado de una sola vez, no sería necesario valerse de ningún método de interpretación para disipar el escándalo. En lo que toca a la poesía de Homero, los presocráticos no podían borrarla enteramente del horizonte griego: Jenófanes mismo vivía de ella; la recitaba por la vía pública.

De acuerdo con esto, los presocráticos debían buscar una forma de "arreglárselas" con el mito a sabiendas de que éste no desaparecería (y, tal vez, deseando su permanencia para que tampoco se esfumara el motivo de queja). En ese sentido, el método alegórico de interpretación ofrece la ventaja de no eliminar del todo lo alegorizado por medio de la alegoría. Más bien sucede que el objeto de la interpretación alegórica se moraliza. En efecto, al verse forzado a coexistir con la alegoría, ésta prevalece sobre lo alegorizado.

No es necesario insistir más en el aporte de los gramáticos a la crítica presocrática. De manera general, se puede decir que el logos, entendido como reverso del mito, es el primer fruto del método alegórico de interpretación. Esto quiere decir que el logos es alegoría del mito.

Para que esto fuera posible, el logos tuvo que ser presentado de manera distinta: no ya como sinónimo de mito, sino como lo contrario de éste. Es sobre semejante contradicción que se funda el término mitología. De no ser por esto, la palabra mitología sería tan sólo una redundancia. Pero el logos que aquí está en juego es la alegoría del mito. Gracias a la conjunción contradictoria de ambos términos -la llamada tensión mitológica- y bajo la consideración de que el mito no puede dar cuenta de sí mismo, el logos ha venido funcionando en Occidente como custodia permanente del mito.

Éste es, en pocas palabras, el balance de la crítica presocrática del mito. Es justo reconocer que todo este esfuerzo moralista se vino abajo por primera vez también entre los griegos, y en menos de dos siglos, al estrellarse contra la obra de Platón y Aristóteles. En lo que respecta a la tensión mitológica, a la pugna entre mito y logos, estos autores no son la feliz culminación del punto de vista presocrático, como ha pretendido establecer la tradición filosófica y los helenistas cuando se refieren al milagro griego, sino más bien el regreso a un estado de indeterminación del logos con respecto al mito. 


\section{Mito y pasiones}

He dado todo este rodeo para situar las pasiones en relación con el mito y para mostrar cómo su problemática es una variante de la tensión mitológica o, si se prefiere, el antecedente de ésta.

Del vínculo entre mito y pasiones, visible en los poemas de Homero, proviene el ya mencionado escándalo presocrático. Lo que verdaderamente molestó a estos filósofos fue que, gracias al politeísmo antropomórfico, la divinidad no se mostraba impasible. La crítica del mito levantada en torno a Homero es, entonces, la primera crítica de las pasiones.

De lo anterior se sigue que la mitología en el fondo no sea otra cosa que una patología. La consideración presocrática del mito como una enfermedad y del logos como un remedio contra el mito confirma este dictamen.

Ahora bien: las consideraciones antiguas sobre las pasiones (del mismo modo que las consideraciones modernas) rara vez se realizaron en relación con el mito. Más bien se puede decir que las pasiones han sido abordadas por sí solas. Sin embargo, la aplicación del método alegórico de interpretación ha llevado, en este caso, a resultados no menos mitológicos. Para decirlo en pocas palabras: la ética ha sido en buena medida la mitología de las pasiones.

Posicionado en el terreno de la ética, Aristóteles enfrenta un curioso problema: el no poder definir las virtudes sin antes hacer un estudio y una clasificación de las pasiones.

Anteriormente, los aspectos fundamentales en torno a las pasiones eran los siguientes: en primer lugar, la atribución del origen del mundo a las pasiones y la consiguiente equivalencia entre éstas y aquél; en segundo lugar, la búsqueda de una parte del cuerpo humano que sirviera de asiento a las pasiones.

El primer aspecto fue planteado por los presocráticos. Las pasiones que entonces fueron puestas como causa del mundo fueron el amor y el odio. Una vez creado el mundo, estas pasiones no desaparecen sino que dan lugar en el horizonte humano al placer y al dolor.

En cuanto a la preocupación por ubicar las pasiones en algún lugar del cuerpo o encontrarles una causa fisiológica, Diógenes de Apolonia se decidió por los humores e Hipócrates, por el cerebro.

Siguiendo una línea similar, el socratismo promulgó una tripartición del cuerpo en la cual la cabeza es el lugar de lo impasible, por dar cobijo al intelecto, mientras que las pasiones residen en el pecho (zona irascible) y en el vientre (región concupiscente). Este planteamiento de la tripartición del cuerpo encuentra un perfeccionamiento en el mito del auriga cuyo carro es guiado por dos caballos, uno manso y otro díscolo, a través del mundo de las ideas. En el mito griego, el auriga es nada menos que el alma, el caballo manso representa la virtud y el fogoso es el deseo y la pasión. El debatimiento constante de pasiones y virtudes tiene lugar, según esto, en esa cárcel del alma que desde entonces es el cuerpo.

El mundo de las ideas en que se pasea el alma antes de precipitarse sobre la vida terrestre, también conocido como mundo inteligible, es la contraparte de ese otro mundo en que se pasea el cuerpo: el mundo sensible. Dejemos en este punto planteada una pregunta para moralistas: si en el origen del mundo están las pasiones y éstas no tienen que ver con la razón, ¿cómo se explica la existencia de un mundo inteligible?

La distinción entre cuerpo y alma tardó menos en ser refutada por primera vez que la distinción entre mito y logos, en la medida en que es menor el espacio de tiempo que va de los 
presocráticos a Platón que el existente entre Platón y Aristóteles. En efecto, la crítica y temporal abolición de esta dicotomía es aristotélica. No fue, por lo tanto, por medio de la distinción cuerpo-alma, inscribiendo en el cuerpo las pasiones y en el alma los vicios, como Aristóteles abordó las pasiones sino desde esa mitología que es la ética. Y lo hizo como preámbulo sin el cual no hubiera podido hacerse cargo de las virtudes.

Con todo, Aristóteles proporciona algo que no se encuentra en ningún filósofo griego anterior: una reflexión sobre las pasiones por completo indiferente a la preocupación moral. Esta reflexión es el resultado de un movimiento que va de la ética a la retórica y se concentra en la semejanza de valor que tienen los caracteres ante las pasiones.

Fuera de la retórica aristotélica, el mundo antiguo no ofrece un tratamiento propiamente inmoralista de las pasiones, excepto en el discurso poético. Son más bien las consideraciones de tipo moral agudizadas en la ética las que dan cuenta del universo pasional.

La función lógica ejercida sobre las pasiones es la misma que interviene sobre el mito. La ética, en la medida en que no es otra cosa que una mitología de las pasiones, establece controles y fija los modelos de conducta virtuosa por medio de los cuales se ha de alcanzar el dominio de las pasiones. En este punto, la mitología desemboca en ascetismo.

El ideal del sabio en la época helenística -y acaso también en todas las épocas- es apenas una muestra de ese efecto mitológico de la ética sobre las pasiones al que comúnmente se da el nombre de ascetismo. Tanto la ataraxia epicúrea como la apatía estoica se definen igualmente como un estado del que han sido desterradas las pasiones.

En este contexto, las pasiones son entendidas abiertamente como lo contrario de la razón y se constituyen, por lo tanto, en las responsables de la ignorancia entre los hombres. La equivalencia entre pasiones y mundo sensible es la causa de que se atribuya a las pasiones la facultad de motivar el engaño del juicio a partir de representaciones falsas. En el camino del sabio hacia una anhelada permanencia en el mundo inteligible se interponen las pasiones. De no ser por éstas, los mundos inteligible y sensible permanecerían del todo incomunicados.

Volvamos a la pregunta para moralistas que más arriba dejamos enunciada. Entre los presocráticos fue planteado por primera vez que el origen del mundo ha sido pasional. Ahora bien, fueron también los presocráticos los primeros en plantear el dualismo de ese mundo. La pregunta era cómo explicar la existencia de un mundo inteligible toda vez que pasiones y razón se ven obligadas a participar en una relación de mutua exclusión.

La respuesta que a esta pregunta dieron los estoicos no es extraña si se considera que para responderla no había mucho que agregar al mito del alma que se pasea por el mundo de las ideas. Sin embargo, debe repararse en la rara mezcla de socratismo y aristotelismo que requirieron los estoicos para afirmar la existencia de pasiones en el alma.

Del mito socrático del alma subida en un carro que vuela por el mundo de las ideas tenemos ya la vinculación entre mundo inteligible y alma. Tenemos también un vínculo entre alma y pasión a pesar de que el socratismo, por medio de la distinción cuerpo-alma, propenderá más bien a ubicar la pasión en el cuerpo, de acuerdo con su ya mencionada tripartición.

Por otra parte, Aristóteles no sólo se sirvió de un punto de vista retórico para ocuparse de las pasiones sin tener que moralizar. También se debe al filósofo de Estagira el haber suspendido la distinción entre alma y cuerpo puesta en boga por el socratismo.

La maniobra estoica depende, pues, de la no separación aristotélica del cuerpo y del alma (para poder pasar con las pasiones del uno a la otra) y del peso de la moral socrática (para 
seguir pensando las pasiones como algo censurable). Para ser más exactos: los estoicos no se conformaron con la consideración de las pasiones como malas en sí mismas. Al hacer del alma también un espacio pasional, no abandonaron la opinión generalizada de la pasión como enfermedad del alma. Sólo que el paliativo, en este caso, no es el mero sometimiento de las pasiones a la razón, sino su radical extirpación.

Sin embargo, como sucede con el mito, extirpar también las pasiones resulta imposible. En todas las dicotomías mencionadas, lo que ha estado en juego es la aplicación del método alegórico de interpretación. Los términos mundo inteligible, virtud, alma, bien -y los que a partir de ahora se quiera agregar a una lista que, por lo demás, Occidente se ha encargado de no cerrar- son todos alegorías, respectivamente, de los siguientes términos: mundo sensible, vicio, cuerpo, mal. Del método alegórico conviene recordar que no agota los objetos con su aplicación.

Ahora bien, el éxito del método alegórico de interpretación en Occidente se debe a que el cristianismo, desde el principio, lo hizo suyo. El motivo por el cual esto sucedió dista mucho de ser un misterio: la vertiente religiosa de la crítica presocrática, con la complicidad de los gramáticos de la época, había sido capaz de revestir el mito con una moralización. El cristianismo simplemente se posicionó de esta vertiente, identificó a Cristo con el logos y se definió a sí mismo como la superación del mito a través del logos. Así, en el plano más general de la religión como institución, el llamado paganismo también fue alegorizado. El cristianismo es el resultado de este proceso.

En cuanto al método mismo, en manos del cristianismo se volvió más sutil, sin perder en ningún momento sus rasgos distintivos: el dualismo del sentido y la dimensión de profundidad. Como extremos de la invariabilidad fundamental del método alegórico durante la Edad Media, tomemos a Orígenes y a Tomás de Aquino como ejemplos.

Al llamar somático al sentido literal y espiritual al sentido alegórico, Orígenes dio carácter explícito a la distinción cuerpo-alma. Procediendo sobre la renominación anterior, Tomás de Aquino hizo una tripartición ya no del cuerpo sino del espíritu en la medida en que del sentido espiritual provienen los tres sentidos que siguen: alegórico, moral y anagógico.

La preocupación por ubicar las pasiones en algún lugar del cuerpo tampoco desapareció. Puede notarse en autores como Juan Damasceno o Tertuliano. Sólo mediante la alegoría sería admitido lo escandaloso. Tertuliano se atrevió a afirmar que incluso en Dios tienen lugar las pasiones y Agustín de Hipona a añadir que el origen de las pasiones es el amor. Pero en el cristianismo lo que está en juego es una alegoría del amor y, por supuesto, también esa alegoría de las pasiones a la que de manera más o menos arquetípica se le da el nombre de Pasión.

Tomás de Aquino no hablará ya de mundo sensible y mundo inteligible, porque ahora recae sobre el mundo una condena inexorable. Hablará más bien de apetito sensitivo y apetito intelectual. Al primero competen las pasiones; al segundo, la voluntad. Para que toda la maquinaria alegórica fuera puesta en marcha con este nuevo ropaje, bastó con afirmar que la voluntad debía doblegar las pasiones.

Del mismo modo en que los gramáticos alegaban que la poesía de Homero resultaba indecente tan sólo porque no se leía alegóricamente, Tomás de Aquino concluyó que los estoicos renegaron de las pasiones porque no las consideraron moralmente. Si las hubieran considerado de ese modo, habrían descubierto la bondad que las anima. Evidentemente, para que las pasiones no resultaran malas, hubo que alegorizarlas. 
La alegorización de las pasiones no desaparece cuando la Edad Media llega a su término. Antes puede decirse que encuentra un reforzamiento en un curioso texto de Descartes titulado Las pasiones del alma.

\section{Hacia la consideración retórica del Diablo}

Durante mucho tiempo se pensó que entre la filosofía de Descartes y sus predecesores había un vacío insalvable. Ahora se sabe que nunca hubo tal vacío. Descartes es tan deudor del Medievo como éste lo es del mundo antiguo. En ese sentido, se ha llegado incluso a pensar que Descartes hizo de la duda su método filosófico tan sólo para encubrir la procedencia griega de no pocas ideas cristianas.

Así, en Descartes encontramos los mundos sensible e inteligible, de alcurnia presocrática, o los apetitos sensitivo e intelectual con otros nombres: la res extensa y la res cogitans. Mediante esta renominación, Descartes reactivó en el campo filosófico una distinción que, luego de ser abolida por Aristóteles, solamente el socratismo y el cristianismo habían desenterrado: la de cuerpo y alma. No es sorprendente, por lo tanto, que Descartes ubicara las pasiones en este contexto, ni resulta novedoso que buscara también un soporte corporal de las pasiones, como habían hecho Diógenes de Apolonia e Hipócrates, sólo que decidiéndose en este caso por la glándula pineal.

Con respecto a las dos vertientes por medio de las cuales la crítica presocrática se afianzó ante el mito, una científica y otra religiosa, el cristianismo resultó ser una reducción. Su interés por combatir el mito no ha dejado de ser meramente religioso. Con Descartes, el punto de vista presocrático simplemente se completa: a la vertiente religiosa que el cristianismo había retomado se suma ahora la vertiente científica de la crítica presocrática del mito. Se trata en ambos casos del mismo logos, del logos que resulta de alegorizar el mito.

Los presocráticos se ocuparon de la naturaleza. Para expresar esto con cierto rigor etimológico, tendríamos que decir que eran ante todo físicos y que, en sus escritos, la física, por mediación de la teología, siempre estuvo en contacto con la moral. En Descartes, puede verificarse la misma conexión y a veces, incluso, el hecho de que fuera la física no solamente un correlato ineludible sino el verdadero soporte de la moral.

Vemos, pues, que, a pesar del alarde levantado en torno a la duda como principio metódico, si hubo alguien que no dudó de sus predecesores fue precisamente Descartes. En el fondo, Descartes no quería dudar o, para decirlo con mayor precisión, quería dudar para dejar de dudar, quería dudar para encontrar algo de lo que ya no tuviera que dudar. Sabemos, por el propio Descartes, que fue su terror a la duda lo que lo condujo a las matemáticas y lo hizo abandonar por completo el estudio de las letras. Recordemos que la alegoría es, en el fondo, el desprecio de las letras, del sentido literal. Digo esto porque en Descartes el sentido profundo de las cosas es, de manera más o menos pitagórica, una matemática universal como fundamento de todo saber.

Descartes no dudó, pues, de la tradición. Pero desde las primeras líneas del tratado Las pasiones del alma arremete contra ella. Reclama a todos sus predecesores en el tema, fundamentalmente a Aristóteles y a la escolástica que encabeza Tomás de Aquino, el no haberse ocupado de las pasiones de manera sistemática y el haber introducido consideraciones morales. Pero 
Descartes miente en ambos casos de manera muy evidente. Aristóteles es precisamente ese sistematizador de las pasiones sin el cual Tomás de Aquino no hubiera conseguido nunca una sistematización todavía mayor.

En cuanto a la introducción de consideraciones morales en el tema de las pasiones, Descartes parece haber pasado por alto el hecho de que fuera hasta ese momento Aristóteles el único autor capaz de ocuparse de las pasiones en una doble dirección: de manera moralista cuando su preocupación era ética y al margen de la moral cuando su interés se volcó hacia la retórica.

Recordemos ahora el problema que tuvo Aristóteles a la hora de definir las virtudes. Dijimos que esta definición Aristóteles no pudo hacerla sin pasar previamente por una consideración sistemática de las pasiones. Descartes pasó por una dificultad similar. El objetivo de la duda cartesiana era, repitámoslo, encontrar algo de lo que no fuera posible dudar. Ese algo era Dios, y es en este punto donde Descartes se encuentra ante un problema similar al de Aristóteles: para definir a Dios, Descartes tuvo que valerse del Diablo a modo de hipótesis. Y si aceptamos que Dios es virtuoso - sumando la dificultad cartesiana a la dificultad aristotélicalas pasiones y el Diablo están en un mismo nivel y son una sola cosa.

La palabra Diablo es de origen griego, proviene del sustantivo diábolos que, a su vez, está relacionado con el término diabolé. Este se utilizaba entre los griegos para hacer referencia a un conjunto de procedimientos cuya aplicación era manifiesta sobre todo en los tribunales. Ejercer la diabolé equivale a poner en duda lo que otra persona diga o pueda decir. Quien ejerce esta habilidad para llevar la sospecha al discurso ajeno, el agente de la diabolé, es precisamente el diábolos. Se trata, pues, de un contexto judicial, pero también retórico. Ya se sabe: el arte retórico empezó en los tribunales, por el siglo $\mathrm{V}$ a. C., y la diabolé formaba parte de ese arte. Como cualquier figura retórica, la diabolé era objeto de una enseñanza; aparece, por ejemplo, en el libro tercero del manual que Aristóteles dedica a esta materia.

Entre cristianos, los términos diabolé y diábolos comenzaron a perder su antigua nobleza retórica. Se entendió por diabolé “calumnia” y por diábolos “calumniador”, bajo el presupuesto de que Dios está en posesión de la verdad; se entendió por diabolé "división” y se hizo del diábolos el "responsable de todo distanciamiento", para que el reino de Dios se perdiera y los hombres se vieran forzados a recuperarlo; se entendió por diabolé "enemistad" y el diábolos se convirtió en el "enemigo" de Dios, de modo que la vida no dejara de ser un enfrentamiento constante con el Diablo.

A la par de tales significados podemos leer también la languidez constitutiva de la verdad que se arroga Dios en tanto que ésta puede ser amenazada; o también el encono declarado contra la sospecha, dado que conduce a un posicionamiento crítico; o también el furor que se descarga contra la duda porque no habría peor enemigo de la fe.

Entender el Diablo y lo diabólico en su sentido retórico nos lleva a planteamientos tal vez inusitados. Así, por ejemplo, una filosofía como la de Descartes, al hacer de la duda su centro de gravedad, debería ser, en principio, diabólica, y no meramente un acto fallido con respecto a la duda. Igualmente, a partir del sentido retórico del Diablo y lo diabólico comprendemos mejor las primeras reacciones -y no solamente las primeras- que suscitaron los escritos de Marx, Freud y Nietzsche. Es, desde luego, un acierto que Ricoeur, al referirse a estos autores por medio de una denominación común, escogiera precisamente la expresión "escuela de la sospecha”. Cada uno de estos autores es diabólico a su manera y en un inevitable sentido retórico. 
Corrijamos ahora a Descartes en la medida en que el Diablo no es una hipótesis. La hipótesis, valga decir la alegoría, es Dios.

\section{Nota}

1. Este texto fue presentado el 6 de octubre de 2001 en "Las Figuras de la Pasión”: VI Jornadas Clínicas de la Asociación Costarricense para la Investigación y el Estudio del Psicoanálisis. Para esta publicación, hemos agregado una bibliografía mínima y suprimido algunos comentarios de orden disgresivo o meramente circunstancial.

\section{Bibliografía}

Aristóteles. 1994. Retórica. Madrid: Editorial Gredos, S. A.

1995. Ética nicomáquea. Ética eudemia. Madrid: Editorial Gredos, S. A.

Barnes, Jonathan. 1993. Aristóteles. Madrid: Ediciones Cátedra, S. A.

Colli, Giorgio. 2000. El nacimiento de la filosofía. Barcelona: Tusquets Editores, S. A.

Descartes, René. 1997. Las pasiones del alma. Madrid: Editorial Tecnos, S. A.

Gomperz, Theodor. 2000. Pensadores griegos. Barcelona: Empresa Editorial Herder, S. A.

Heráclito (el Rétor). 1989. Alegorías de Homero. Madrid: Editorial Gredos, S. A.

Platón. 1997. Diálogos. Madrid: Editorial Gredos, S. A.

Szlezák, Thomas. 1997. Leer a Platón. Madrid: Alianza Editorial, S. A.

Taylor, A. E. 1993. El pensamiento de Sócrates. México: Fondo de Cultura Económica.

Vignaux, Paul. 1983. El pensamiento en la Edad Media. México: Fondo de Cultura Económica.

Williams, Bernard. 1996. Descartes. Madrid: Ediciones Cátedra, S. A. 